\title{
A Solid-State Fluorescence Switch Based on Triphenylethene-Functionalized Dithienylethene With Aggregation-Induced Emission
}

\author{
Haining Zhang ${ }^{1}$, Xiaoxiao Hu ${ }^{1}$, Huijuan Zhu ${ }^{1}$, Limin Shen ${ }^{1}$, Congmin Liu ${ }^{1}$, \\ Xiaoman Zhang ${ }^{1}$, Xinyu Gao ${ }^{1}$, Lingmei $\mathrm{Li}^{1}$, Yan-Ping $\mathrm{Zhu}^{2 *}$ and Ziyong $\mathrm{Li}^{{ }^{*}}$ \\ ${ }^{1}$ Luoyang Key Laboratory of Organic Functional Molecules, College of Food and Drug, Luoyang Normal University, Luoyang, \\ China, ${ }^{2}$ Key Laboratory of Molecular Pharmacology and Drug Evaluation, Ministry of Education, Collaborative Innovation \\ Center of Advanced Drug Delivery System and Biotech Drugs in Universities of Shandong, School of Pharmacy, Yantai \\ University, Yantai, China
}

OPEN ACCESS

Edited by:

Ralph Ernstorfer,

Fritz-Haber-Institut, Germany

Reviewed by:

Haiyin Li,

Qingdao Agricultural University, China

Tsz Kin Kwok

Hong Kong University of Science and

Technology, Hong Kong

*Correspondence:

Ziyong L

liziyong@mails.ccnu.edu.cn

Yan-Ping Zhu

chemzyp@foxmail.com

Specialty section

This article was submitted to

Physical Chemistry and Chemical

Physics,

a section of the journa

Frontiers in Chemistry

Received: 15 February 2021

Accepted: 24 March 2021

Published: 28 April 2021

Citation:

Zhang H, Hu X, Zhu H, Shen L, Liu C,

Zhang $X$, Gao X, Li L, Zhu Y-P and Li Z

(2021) A Solid-State Fluorescence

Switch Based on

Triphenylethene-Functionalized

Dithienylethene With

Aggregation-Induced Emission

Front. Chem. 9:665880.

doi: 10.3389/fchem.2021.665880
The development of novel dithienylethene-based fluorescence switches in the aggregated state, and the solid state is highly desirable for potential application in the fields of optoelectronics and photopharmacology. In this contribution, three novel triphenylethene-functionalized dithienylethenes (1-3) have been designed and prepared by appending triphenylethene moieties at one end of dithienylethene unit. Their chemical structures are confirmed by ${ }^{1} \mathrm{H}$ NMR, ${ }^{13} \mathrm{C}$ NMR, and HRMS (ESI). They display good photochromic behaviors with excellent fatigue resistance upon irradiation with UV or visible light in Tetrahydrofuran (THF) solution. Before irradiation with UV light, they exhibit Aggregation Induced Emission (AIE) properties and luminescence behaviors in the solid state. Moreover, upon alternating irradiation with UV/visible light, they display effective fluorescent switching behaviors in the aggregated state and the solid state. The experimental results have been validated by the Density Functional Theory (DFT) calculations. Thus, they can be utilized as novel fluorescence switches integrated in smart, solid-state optoelectronic materials and photopharmacology.

Keywords: dithienylethene, fluorescence switch, aggregation-induced emission, photochromism, triphenylethene

\section{INTRODUCTION}

In recent years, fluorescence switches have received increasing attention due to their potential applications in super-resolution fluorescence microscopies and optical data storage (Irie et al., 2002; Qiang et al., 2018; Yu et al., 2018). Generally, the elaboration of switch systems combining photochromic unit and fluorescence groups can be modulated with optical stimulations through intramolecular energy/electron transfer (Raymo and Tomasulo, 2005). Dithienylethene (DTE), a family of classic P-type-photochromic compounds, can be reversibly transformed between ring-open and ring-closed isomers by photoirradiation, which is appealing for optical switching of fluorescence on account of high thermal stability, rapid response, and fatigue resistance (Irie, 2000; Irie et al., 2000, 2014; Tian and Yang, 2004; Zhang et al., 2014; Pu et al., 2016; Yao et al., 2016; Lubbe et al., 2017; Zhang and Tian, 2018; Li et al., 2019a; Li Z. et al., 2020). In recent years, great progress has 


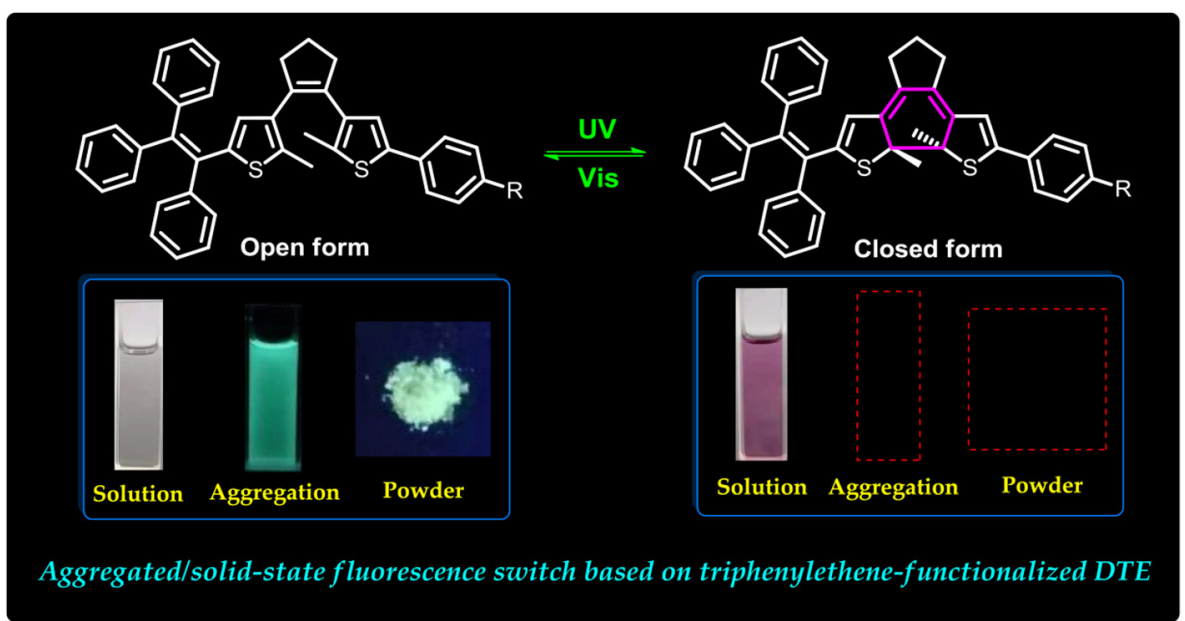

GRAPHICAL ABSTRACT | They displayed effective fluorescent switching behaviors in the aggregated state and solid state.

been made in the fluorescence switches-based dithienylethene unit (Myles et al., 2010; Fukaminato et al., 2011; Uno et al., 2011; Li et al., 2014; Yao et al., 2016). However, most normal fluorophores suffer from fluorescence weakening or quenching at high concentration or in the aggregated state, which is known as "aggregation-caused quenching" (ACQ) caused by the strong intermolecular $\pi-\pi$ interaction or hydrogen bonding between neighboring fluorophores (Cui et al., 2016; Ma et al., 2018; Zhou et al., 2020), thus limiting applications of these photoswitches in the optoelectronics and photopharmacology in the future. Therefore, it will be highly desirable to develop the aggregated/solid-state fluorescence switches for potential applications.

Fortunately, Tang's group discovered a novel class of fluorophores with aggregation-induced emission (AIE) in 2001 (Luo et al., 2001), which is opposite to the conventional ACQ phenomenon. This interesting phenomenon provides a new direction to design organic fluorescent materials with more widely and greater practical applications in the aggregated state or the solid state (Ding et al., 2013; Mei et al., 2014; Liang et al., 2015; Li et al., 2017; Li H. et al., 2020; Li X. et al., 2020; Tian et al., 2020; Zang et al., 2021). To the best of our knowledge, the most simplest approach to achieve the aggregated/solid-state fluorescence switches is combining the photochromic reaction of DTE and fluorescence of solid emitters (such as naphthalimide (Wang et al., 2006; Jiang et al., 2007, 2009), perylene bisimide (Fukaminato et al., 2011; Berberich et al., 2012; Li et al., 2014), tetraphenylethene (Li et al., 2013; Dong et al., 2016; Ma et al., 2020), and cyanosubstituted ethylene (Lim et al., 2004, 2005; Wang et al., 2018) to afford high-contrast fluorescence switches in the aggregated or solid state. Recently, our group has developed a novel, solid-state fluorescence switch triggered by blue light (460$470 \mathrm{~nm})$ and NIR light $(7,600-770 \mathrm{~nm})$, in which carbazole and $\mathrm{BF}_{2} \mathrm{bdk}$ moieties are suspended on both sides of the dithienylethene unit (Li et al., 2019c). However, we still know very little about such aggregated/solid-state fluorescence switches.
Consequently, it is urgently necessary to develop novel DTEbased fluorescence switches in the aggregated state and the solid state for the practical application requirements. In addition to the tetraphenylethene (TPE), the more readily available triphenylethene (TriPE) is also a typical aggregation-inducedemission active group. Herein, we have developed three novel triphenylethene-functionalized dithienylethenes (1-3), as shown in Scheme 1. And their photochromism, AIE properties, and fluorescent switching behaviors in the aggregated state and the solid state have been thoroughly investigated.

\section{MATERIALS AND METHODS}

\section{Materials}

Manipulation is carried out under a nitrogen atmosphere, using standard Schlenk techniques unless otherwise stated. THF was distilled under nitrogen from sodium-benzophenone. The intermediates 4 (Lucas et al., 2003) and 5 (Dong et al., 2016) are prepared by reported literature methods. All other starting materials are obtained commercially as analyticalgrade and used without further purification. The cyclization and cycloreversion quantum yields of dithienylethenes 1-3 are determined by comparing the reaction yield with the known yield of the compound 2-bis(2-methyl-5-phenyl-3thienyl)perfluorocyclopentene (Irie et al., 2000).

\section{Instruments}

${ }^{1} \mathrm{H}$ and ${ }^{13} \mathrm{C}$ NMR spectra are collected on German BRUKER AVANCE III $400 \mathrm{MHz}$ (all the chemical shifts are relative to TMS). High-resolution mass spectra are obtained on SCIEX X500R QTOF (ESI mode). All the absorption spectra are collected on a SHIMADZU UV-2600 UV-Vis spectrophotometer. In the photochromic experiments, UV light irradiation $(254 \mathrm{~nm})$ is carried out, using a ZF5UV lamp; and visible light is irradiated, using an LZG $220 \mathrm{~V} 500 \mathrm{~W}$ tungsten lamp $(\lambda>402 \mathrm{~nm})$ with cut-off filters. 

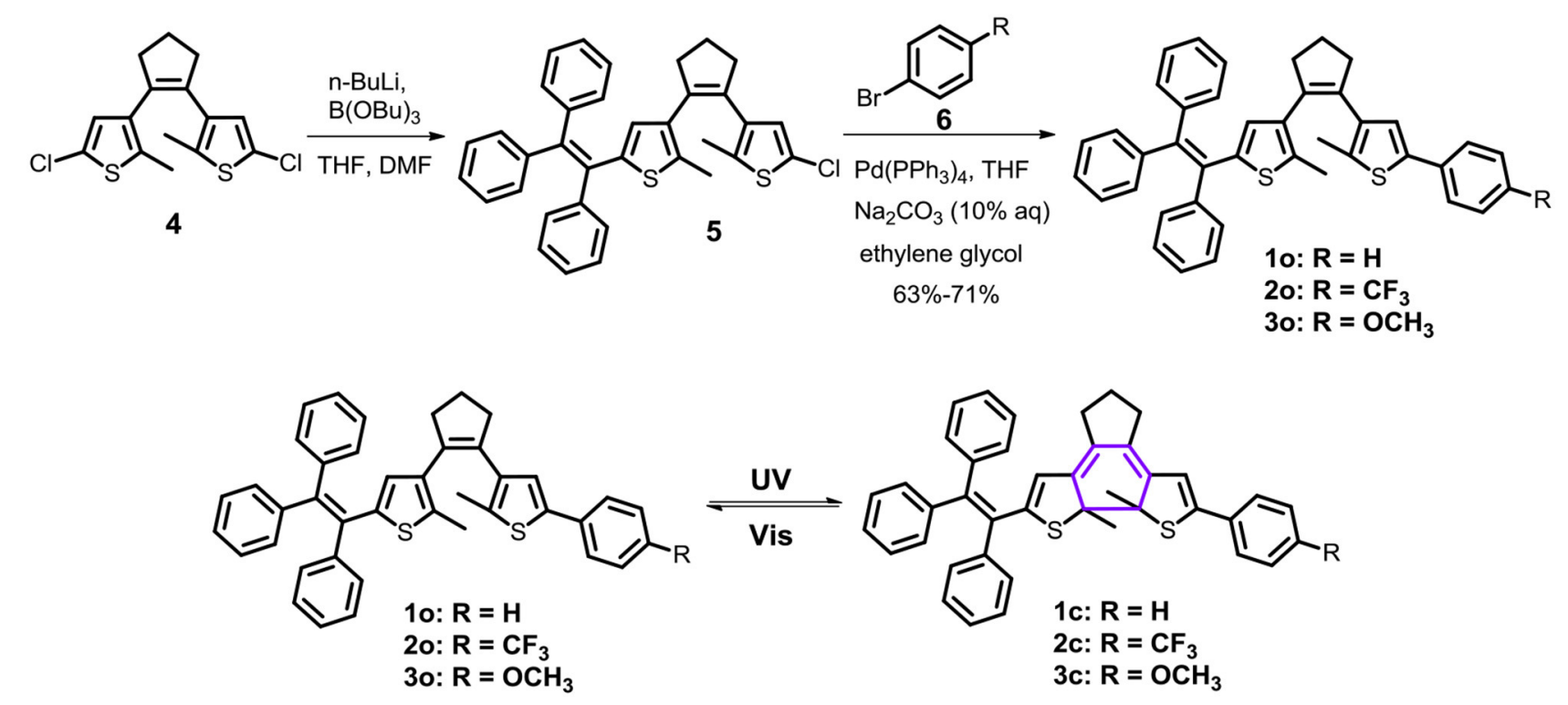

SCHEME 1 | Synthetic route and photochromism of dithienylethenes 1-3.

\section{Synthesis of Dithienylethenes 1-3}

To a solution of $5(548 \mathrm{mg}, 1 \mathrm{mmol})$ in anhydrous THF (10 ml), $n$-BuLi $(0.4 \mathrm{ml}$ of $2.5 \mathrm{M}$ solution in hexane, $1 \mathrm{mmol})$ is slowly added under $\mathrm{N}_{2}$ in an ice bath and stirred for $1 \mathrm{~h}$ at $0^{\circ} \mathrm{C}$. Then $\mathrm{B}(\mathrm{OBu})_{3}(0.41 \mathrm{ml}, 1.5 \mathrm{mmol})$ is added to the above solution and stirred for $6 \mathrm{~h}$ at room temperature. Then, the resultant reddish solution is added dropwise to a solution, containing bromobenzene (156 mg, $1 \mathrm{mmol}), \mathrm{Pd}\left(\mathrm{PPh}_{3}\right)_{4}(25 \mathrm{mg}, 0.02 \mathrm{mmol})$ in THF $(10 \mathrm{ml})$ and $\mathrm{Na}_{2} \mathrm{CO}_{3}(2 \mathrm{M}, 10 \mathrm{ml})$ at $60^{\circ} \mathrm{C}$. The mixture is refluxed for $16 \mathrm{~h}$ under $\mathrm{N}_{2}$. The reaction solution is cooled to room temperature and extracted with ethyl acetate $(3 \times 20 \mathrm{ml})$, and the combined organic layer is washed with the saturated brine $(2 \times 20 \mathrm{ml})$. The organic layer is dried over $\mathrm{Na}_{2} \mathrm{SO}_{4}$, filtered and concentrated under reduced pressure. The residue is purified by column chromatography (silica gel: 200-300, PE) to afford dithienylethene $\mathbf{1}$ as a light yellow solid (Yield: 66\%). ${ }^{1} \mathrm{H}$ NMR $\left(400 \mathrm{MHz}, \mathrm{CDCl}_{3}\right) \delta 7.49(\mathrm{~d}, J=7.6 \mathrm{~Hz}, 2 \mathrm{H}), 7.35$ $(\mathrm{t}, J=7.6 \mathrm{~Hz}, 2 \mathrm{H}), 7.23(\mathrm{br}, 6 \mathrm{H}), 7.11-7.08(\mathrm{~m}, 5 \mathrm{H}), 7.03-$ $7.01(\mathrm{~m}, 3 \mathrm{H}), 6.96-6.93(\mathrm{~m}, 3 \mathrm{H}), 6.28(\mathrm{~s}, 1 \mathrm{H}), 2.73(\mathrm{t}, J=$ $6.3 \mathrm{~Hz}, 2 \mathrm{H}), 2.54(\mathrm{~d}, J=6.4 \mathrm{~Hz}, 2 \mathrm{H}), 1.98-1.94(\mathrm{~m}, 2 \mathrm{H}), 1.92$ (s, 3H), 1.78 (s, 3H). ${ }^{13} \mathrm{C} \mathrm{NMR}\left(100 \mathrm{MHz}, \mathrm{CDCl}_{3}\right) \delta 143.69$, $143.28,142.93,141.76,139.98,139.42,136.66,135.65,134.95$, $134.7,134.57,134.21,134.04,133.99,131.24,130.97,130.94$, $130.8,128.73,128.2,127.56,127.44,126.97,126.89,126.75$, $126.13,125.29,124.04,38.36,38.31,22.86,14.56,14.16$. HRMS (ESI-TOF) $\mathrm{m} / \mathrm{z}:[\mathrm{M}+\mathrm{H}]^{+}$Calcd. for $\mathrm{C}_{41} \mathrm{H}_{35} \mathrm{~S}_{2}^{+} 591.218$; found 591.2152 .

Dithienylethene $\mathbf{2}$ is synthesized by an analogous method to dithienylethene $\mathbf{1}$ as a yellow solid (yield: $71 \%) .{ }^{1} \mathrm{H}$ NMR (400 $\left.\mathrm{MHz}, \mathrm{CDCl}_{3}\right) \delta$ 7.61-7.56 (m, 3H), $7.24(\mathrm{br}, 6 \mathrm{H}), 7.12-7.07(\mathrm{~m}$, $5 \mathrm{H}), 7.01(\mathrm{br}, 4 \mathrm{H}), 6.95-6.93(\mathrm{~m}, 2 \mathrm{H}), 6.26(\mathrm{~s}, 1 \mathrm{H}), 2.73(\mathrm{t}, J=$ $7.2 \mathrm{~Hz}, 2 \mathrm{H}), 2.56(\mathrm{t}, J=7.2 \mathrm{~Hz}, 2 \mathrm{H}), 1.99-1.91(\mathrm{~m}, 2 \mathrm{H}), 1.94(\mathrm{~s}$, $3 \mathrm{H}), 1.78$ (s, 3H). ${ }^{13} \mathrm{C}$ NMR $\left(100 \mathrm{MHz}, \mathrm{CDCl}_{3}\right) \delta 143.84,143.39$, $143.08,142.09,140.29,138.09,137.81,137.29,136.06,135.80$, $135.44,134.99,134.23,134.13,133.77,131.38,131.09,130.97$,
$128.92,128.39,127.75,127.64,127.18,126.95,126.35,125.94$, $125.9,125.67,125.39,38.49,38.45,23.01,14.77,14.31 . H R M S$ (ESI-TOF) $\mathrm{m} / \mathrm{z}:[\mathrm{M}+\mathrm{H}]^{+}$Calcd. for $\mathrm{C}_{42} \mathrm{H}_{34} \mathrm{~F}_{3} \mathrm{~S}_{2}^{+} 659.2054$; found 659.2031.

Dithienylethene3 is synthesized by an analogous method to dithienylethene $\mathbf{1}$ as a yellow solid (yield: 63\%). ${ }^{1} \mathrm{H}$ NMR (400 $\left.\mathrm{MHz}, \mathrm{CDCl}_{3}\right) \delta 7.42(\mathrm{~d}, J=8.7 \mathrm{~Hz}, 2 \mathrm{H}), 7.25$ (br, 5H), 7.12$7.08(\mathrm{~m}, 5 \mathrm{H}), 7.02(\mathrm{br}, 3 \mathrm{H}), 6.95-6.88(\mathrm{~m}, 4 \mathrm{H}), 6.82(\mathrm{~s}, 1 \mathrm{H})$, $6.28(\mathrm{~s}, 1 \mathrm{H}), 3.83(\mathrm{~s}, 3 \mathrm{H}), 2.72(\mathrm{t}, J=7.2 \mathrm{~Hz}, 2 \mathrm{H}), 2.55(\mathrm{t}, J$ $=7.1 \mathrm{~Hz}, 2 \mathrm{H}), 1.98-1.92(\mathrm{~m}, 2 \mathrm{H}), 1.90(\mathrm{~s}, 3 \mathrm{H}), 1.77(\mathrm{~s}, 3 \mathrm{H})$. ${ }^{13} \mathrm{C}$ NMR $\left(100 \mathrm{MHz}, \mathrm{CDCl}_{3}\right) \delta 158.69,143.66,143.26,142.89$, $141.65,139.85,139.26,136.47,135.6,134.98,134.46,134.03$, $133.99,133.12,131.25,131,130.95,130.8,128.2,127.55,127.43$, $126.97,126.75,126.52,126.11,122.89,114.09,55.34,38.34,38.26$, 22.8, 14.5, 14.18. HRMS (ESI-TOF) $\mathrm{m} / \mathrm{z}:[\mathrm{M}+\mathrm{H}]^{+}$Calcd. for $\mathrm{C}_{42} \mathrm{H}_{37} \mathrm{OS}_{2}^{+}$621.2286; found 621.2279.

\section{RESULTS AND DISCUSSIONS}

\section{Photochromic Properties in Solution}

Firstly, photochromic properties of the triphenylethenefunctionalized dithienylethene 1-3 are investigated upon alternating irradiation with $254 \mathrm{~nm}$ UV light and visible light $(>402 \mathrm{~nm}$ ) in THF, which undergo photoisomerization between the open form and the closed form (Scheme 1). As depicted in Figure $1 \mathbf{A}$, the absorption maximum of ring-open isomer $\mathbf{1}$ (o) in THF is observed at $260 \mathrm{~nm}\left(\varepsilon=6.58 \times 10^{4} \mathrm{M}^{-1} \mathrm{~cm}^{-1}\right)$ as a result of a $\pi-\pi^{*}$ transition ( $\mathrm{Li}$ et al., 2008). Upon irradiation with $254 \mathrm{~nm}$ UV light, a new absorption band at $540 \mathrm{~nm}(\varepsilon=$ $0.81 \times 10^{4} \mathrm{M}^{-1} \mathrm{~cm}^{-1}$ ) appears along with an obvious color change from colorless to pink as a result of the formation of the corresponding ring-closed isomer 1 (c) (Scheme 1). Moreover, an obvious isosbestic point that appears at $323 \mathrm{~nm}$ is observed, which indicates a clean photochemical transformation between the open isomer $\mathbf{1}$ (o) and closed isomer $\mathbf{1}$ (c)because 

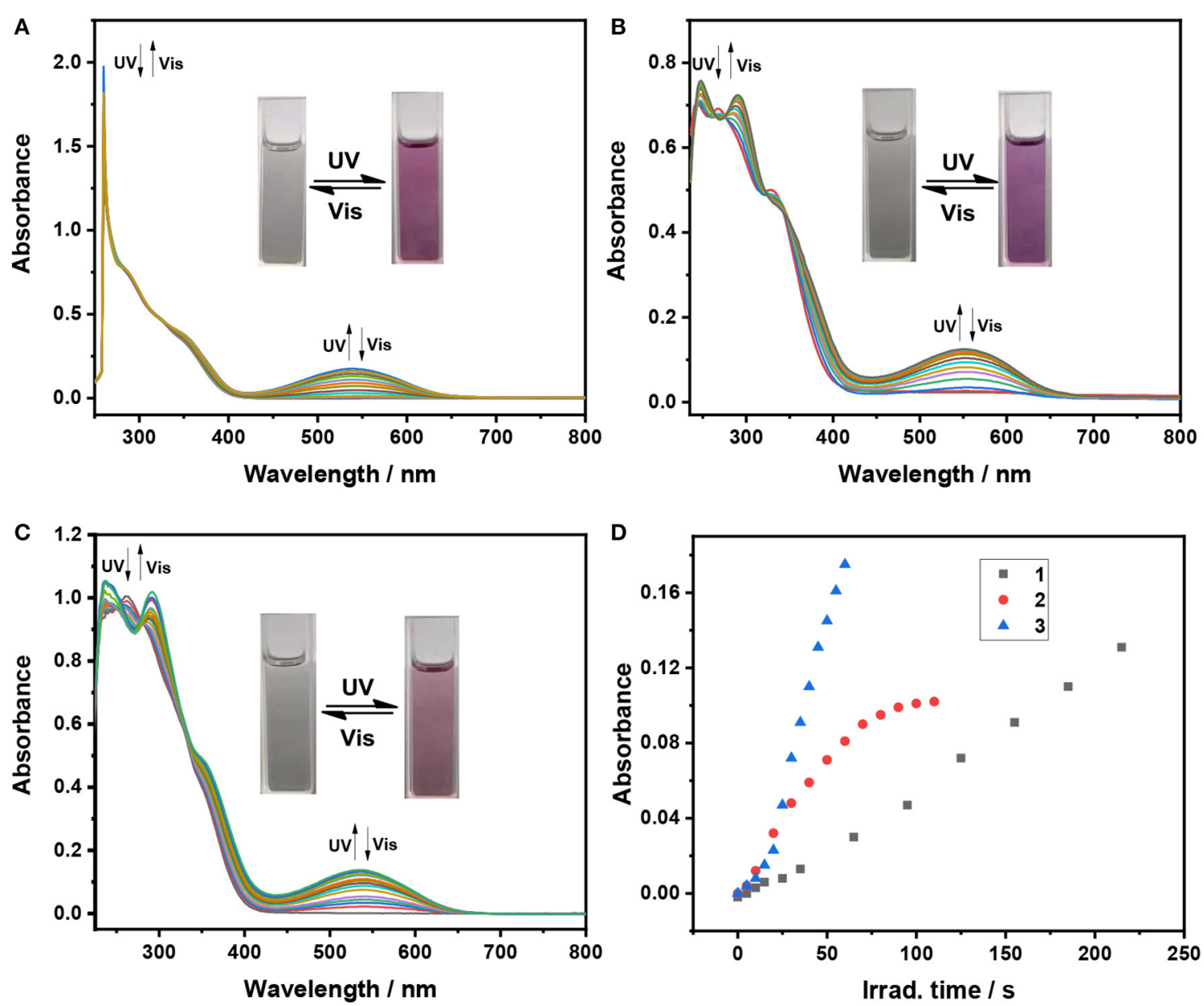

FIGURE 1 | Absorption spectral changes of dithienylethenes 1-3 with $254 \mathrm{~nm}$ UV and $>402 \mathrm{~nm}$ Vis light irradiation in THF (2 $\times 10^{-5}$ mol/L), (A) spectral changes for 1 (0-395 s for cyclization, irradiation interval: $5 \mathrm{~s}$; 0-650 s for cycloreversion, irradiation interval: 10 s); (B) spectral changes for 2 (0-110 s for cyclization, irradiation interval: 5 s; 0-195 s for cycloreversion, irradiation interval: $10 \mathrm{~s})$; (C) spectral changes for $\mathbf{3}$ (0-85 s for cyclization, irradiation interval: $5 \mathrm{~s}$; 0-125 s for cycloreversion, irradiation interval: 10 s); (D) the optical response rate monitored at the maximum absorption wavelength in the visible region for ring-closed isomers $\mathbf{1 c}-\mathbf{3 c}$.

TABLE 1 | Photochromic parameters of dithienylethenes 1-3 in THF $\left(2 \times 10^{-5} \mathrm{M}\right)$ and emission data in the aggregated and powder states.

\begin{tabular}{|c|c|c|c|c|c|c|}
\hline Compounds & $\lambda_{\max } \mathrm{a}(\mathrm{nm})\left(\varepsilon \times 10^{4}, \mathrm{M}^{-1} \mathrm{~cm}^{-1}\right)$ & $\lambda_{\max } b(\mathrm{~nm})\left(\varepsilon \times 10^{4}, \mathrm{M}^{-1} \mathrm{~cm}^{-1}\right)$ & $\phi_{\mathrm{o}-\mathrm{c}} \mathrm{c}$ & $\phi_{c-o} d$ & $\lambda_{\mathrm{em}} \mathrm{e}(\mathrm{nm})$ & $\lambda_{\mathrm{em}} \mathrm{f}(\mathrm{nm})$ \\
\hline & (Open) & (PSS) & & & & \\
\hline 1 & $260(6.58)$ & $540(0.81)$ & 0.13 & 0.0074 & 495 & 493 \\
\hline 2 & 268 (2.51) & $552(0.63)$ & 0.25 & 0.0079 & 491 & 487 \\
\hline 3 & 262 (5.03) & $538(0.69)$ & 0.34 & 0.0084 & 494 & 490 \\
\hline
\end{tabular}

${ }^{a}$ Absorption maxima of ring-open isomers.

${ }^{b}$ Absorption maxima of ring-closed isomers.

${ }^{c}$ The cyclization quantum yields $\left(\phi_{c-0}\right)$.

${ }^{d}$ The cycloreversion quantum yields ( $\left.\phi_{0-c}\right)$.

${ }^{e}$ Emission maxima of ring-open isomers in the aggregated state.

${ }^{f}$ Emission maxima of ring-open isomers in the powder state, respectively.

isosbestic point generally means the coexistence of both open and closed forms. Upon irradiation with $>402 \mathrm{~nm}$ visible light, the pink closed isomer 1 (c) performs a cycloreversion reaction to form the initial colorless open isomer. Particularly, good reversibility for photochromism can be observed upon alternating photoirradiation into the ring-open and ring-closed isomers of dithienylethene 1 (Supplementary Figure 1). The cyclization and cycloreversion quantum yields of $\mathbf{1}$ in THF are.13 $\left(\phi_{\mathrm{o}-\mathrm{c}}\right)$ and $0.0074\left(\phi_{\mathrm{c}-\mathrm{o}}\right)$ (Table 1), respectively.

Similar photochromic behaviors are observed when THF solutions of $\mathbf{2}$ and $\mathbf{3}$ are exposed to $254 \mathrm{~nm} \mathrm{UV} \mathrm{light} \mathrm{and}$ $>402 \mathrm{~nm}$ visible light, respectively, as illustrated in Figures 1B,C, 

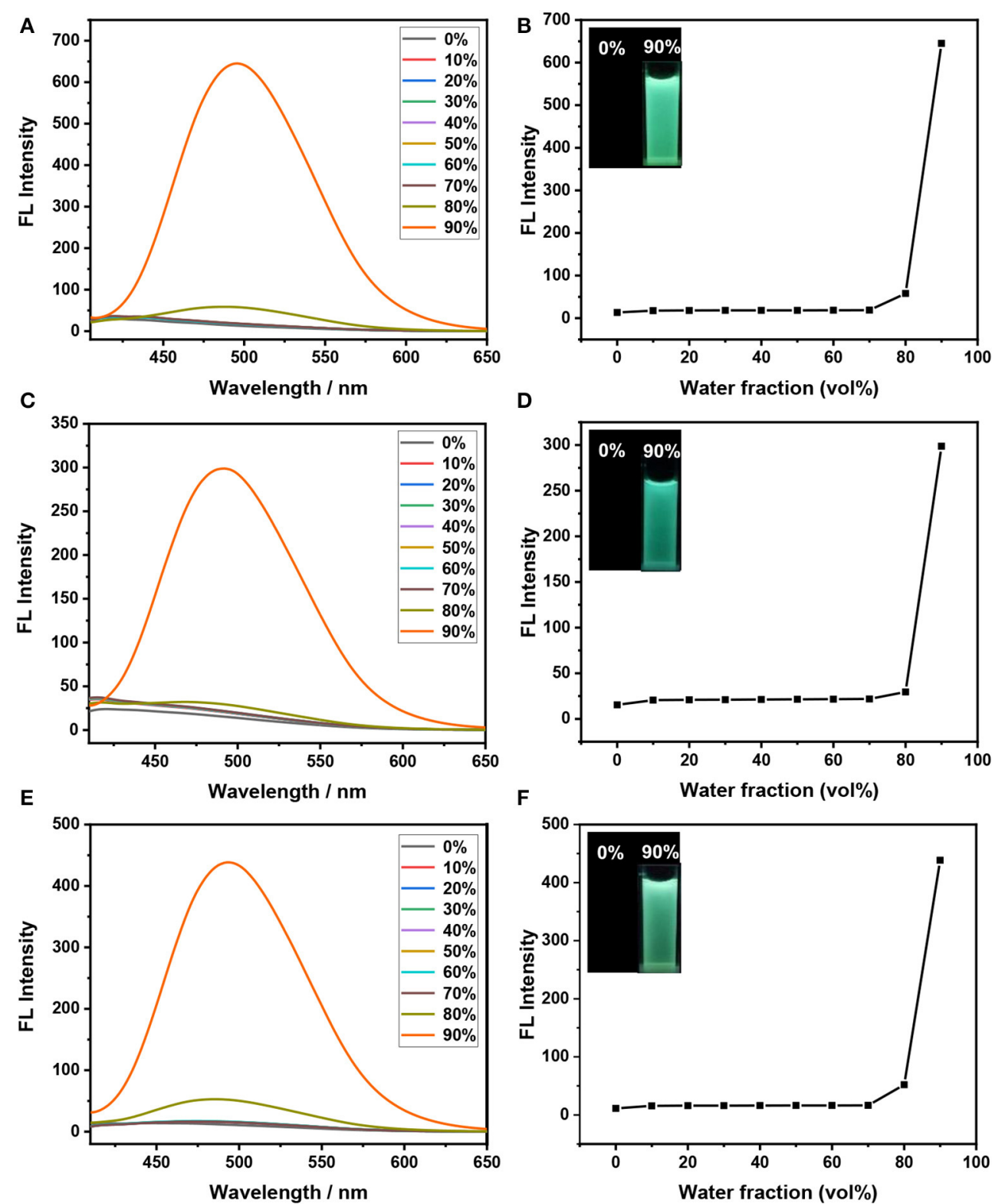

FIGURE 2 | Fluorescence spectra of dithienylethenes 1-3 in different $\mathrm{H}_{2} \mathrm{O} / \mathrm{THF}(\mathrm{V} / \mathrm{V})$-mixed solutions $\left(2 \times 10^{-5} \mathrm{~mol} / \mathrm{L}\right)$ (A,C,E); the dependence of the fluorescence emission intensity on the water fraction ( $\left.f_{w}\right)$ (Insert: photographs of dithienylethenes 1-3 in 0\% and $90 \%$ water solutions under $365 \mathrm{~nm}$ UV light (B,D,F), (A,B) for dithienylethene 1; (C,D) for dithienylethene $\mathbf{2}$; $(\mathbf{E}, \mathbf{F})$ for dithienylethene $\mathbf{3}$.

Supplementary Figures 2, 3. Moreover, their optical response rates into luene are sequenced in the following order in $3>$ $2>1$ (Figure 1D), implying that 3 and 2 can achieve the photo stationary state more efficiently than analog 1 without substitution. The data from Table 1 revealed that different substituent groups have a slight effect on their photochromic properties, mainly including the absorption maximum and quantum yields of cyclization and cycloreversion reactions. For dithienylethene 2 with the trifluoromethyl group, the maximum absorption wavelengths of ring-open isomer [ $268 \mathrm{~nm}$ for 2 (o)] and ring-closed isomer [552 $\mathrm{nm}$ for 2 (c)] display a distinct bathochromic shift compared with those of 1a without substitution and $\mathbf{3}$ with the $\mathrm{OCH}_{3}$ group, which can be attributed to the fact that the $-\mathrm{CF}_{3}$ group can reduce the HOMO-LUMO energy gap for the open and closed isomers. As expected, their cyclization quantum yields $\left(\phi_{\mathrm{o}-c}\right)$ are much higher than their respective cycloreversion quantum yields $\left(\phi_{\mathrm{c}-\mathrm{o}}\right)$, which is in accordance with other reported photochromic dithienylethenes (Li et al., 2019b,d,e). Moreover, $\phi_{\mathrm{o}-\mathrm{c}}$ and $\phi_{\mathrm{c}-\mathrm{o}}$ of dithienylethene 3, with the $\mathrm{OCH}_{3}$ group, are higher compared with those of $\mathbf{1}$ and 2, for example, $\phi_{\mathrm{o}-\mathrm{c}}=0.34, \phi_{\mathrm{c}-\mathrm{o}}=0.0084$ for 3, $\phi_{\mathrm{o}-\mathrm{c}}$ $=0.13, \phi_{\mathrm{c}-\mathrm{o}}=0.0074$ for $1, \phi_{\mathrm{o}-\mathrm{c}}=0.25, \phi_{\mathrm{c}-\mathrm{o}}=0.0079$ 

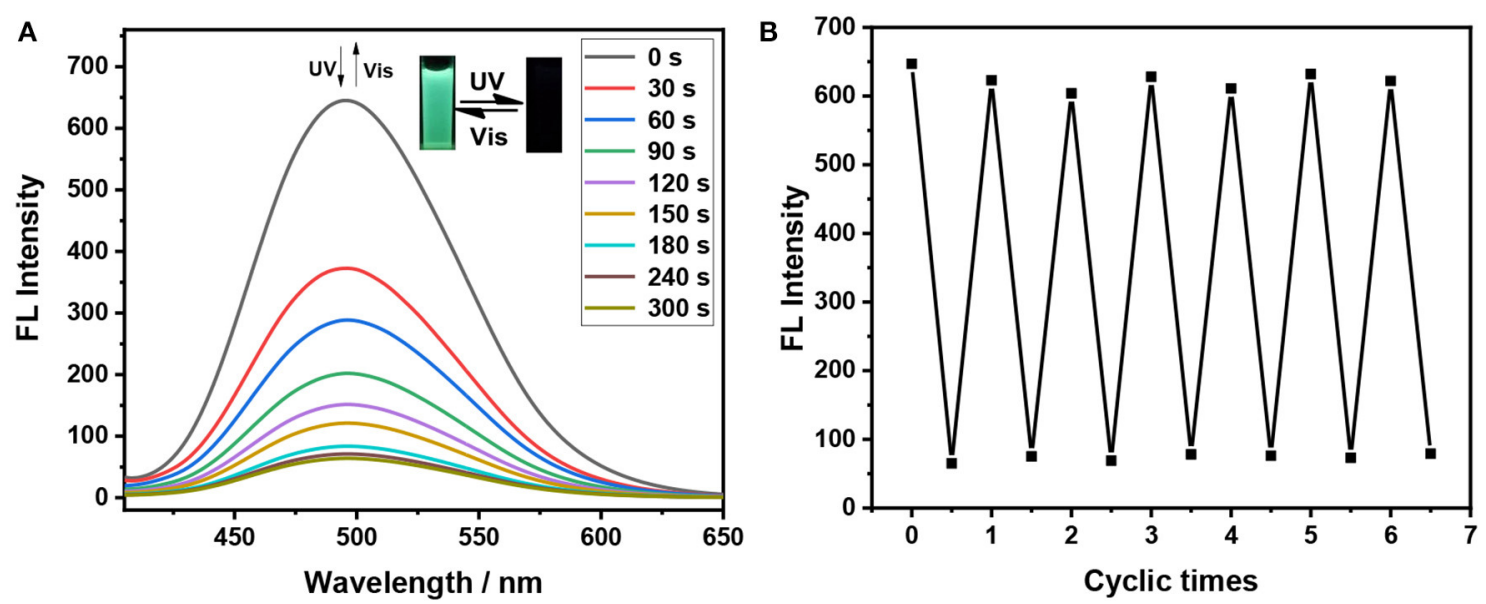

FIGURE 3 | Fluorescence spectra changes of dithienylethene $\mathbf{1}$ in the mixtures of $\mathrm{H}_{2} \mathrm{O} / \mathrm{THF}\left(\mathrm{f}_{W}=90 \%\right)\left(2 \times 10^{-5} \mathrm{~mol} / \mathrm{L}\right)$ upon alternating irradiation with UV light (0-300 s for the fluorescent-off state, irradiation interval: $30 \mathrm{~s}$ ) at $254 \mathrm{~nm}$ and visible light at $>402 \mathrm{~nm}$ (0-450 s for the fluorescent-on state, irradiation interval: 50), (A) (Inset) Corresponding fluorescent color changes upon photoirradiation in the powder state; reversible fluorescence switching for $\mathbf{1}$ in the mixtures of $\mathrm{H}_{2} \mathrm{O} / \mathrm{THF}\left(f_{w}=\right.$ $90 \%)\left(2 \times 10^{-5} \mathrm{~mol} / \mathrm{L}\right)$, measured at $495 \mathrm{~nm}$ upon alternating irradiation with UV light at $254 \mathrm{~nm}$ and visible light at $>402 \mathrm{~nm}$ (B).
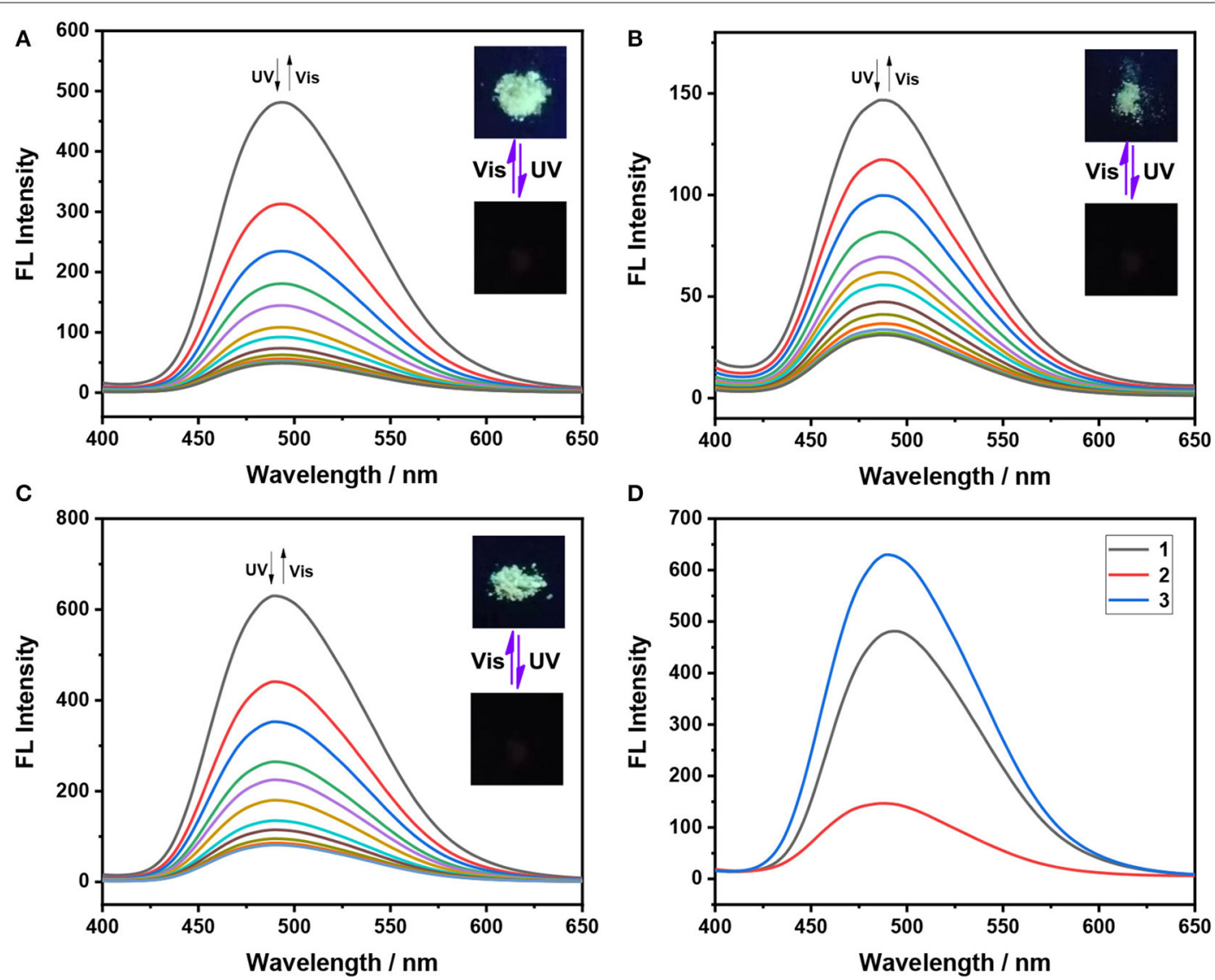

FIGURE 4 | Fluorescence spectra changes of dithienylethenes 1-3 in the solid state upon alternating irradiation with UV light at $365 \mathrm{~nm}$ and visible light at $>402 \mathrm{~nm}$, (A) spectral changes for $\mathbf{1}$ (0-800 s for the fluorescent-off state, irradiation interval: $40 \mathrm{~s}$; 0-1,200 s for the fluorescent-on state, irradiation interval: $60 \mathrm{~s}$ ); (B) spectral changes for 2 ( $0-560$ s for the fluorescent-off state, irradiation interval: 40 s; 0-960 s for the fluorescent-on state, irradiation interval: 60 s); (C) spectral changes for 3 ( $0-480$ s for the fluorescent-off state, irradiation interval: 40 s; 0-720 s for the fluorescent-on state, irradiation interval: 60 s); (D) fluorescence emission spectra of ring-open isomers 10-3o in the solid state. (Inset) Corresponding fluorescent color changes upon photoirradiation in the powder state. 


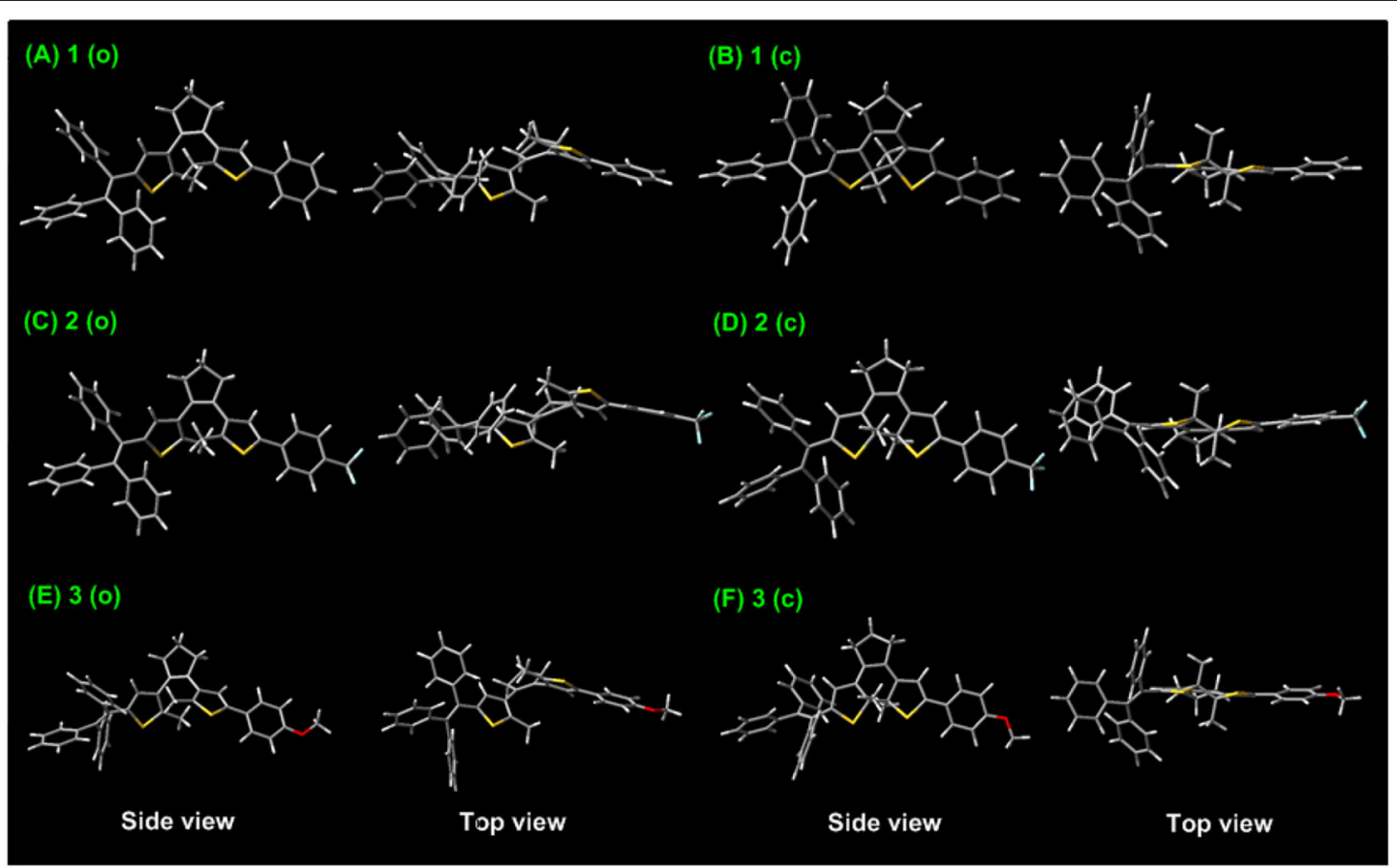

FIGURE 5 | Optimized ground-state geometry of dithienylethenes 1-3 based on DFT calculations at the B3LYP/6-31G* level by using the Gaussian 09 program, (A) ring-open isomer 1 (O); (B) ring-closed isomer 1 (C); (C) ring-open isomer 2 (O); (D) ring-closed isomer 2 (C); (E) ring-open isomer 3 (o); (F) ring-closed isomer 3 (C).

for $\mathbf{2}$. Accordingly, $\mathbf{2}$ and $\mathbf{3}$ display much better photochromic properties than $\mathbf{1}$ without substitution.

\section{AIE Properties of Dithienylethenes 1-3}

Subsequently, the AIE properties of these triphenylethenefunctionalized dithienylethenes (1-3) are explored before irradiation with UV light at $254 \mathrm{~nm}$. As illustrated in Figure 2A, the open form 1 (o) displays almost no emission in pure THF solution, meaning the three phenyl rings o nTriPE moieties can effectively dissipate the excited-state energy via intramolecular rotations. The emission spectra remain almost constant when the water fraction $\left(f_{w}\right)$ gradually increased from 0 to $70 \%$. As $f_{w}$ further increases, the fluorescent emission intensity at $495 \mathrm{~nm}$ is enhanced and reaches its maximum when $f_{w}$ is $90 \%$, which is accompanied by green fluorescence (Figure 2B). We think the main reason for this phenomenon is that the propellershaped triphenylethene moieties with non-planarity prevent intermolecular $\pi-\pi$ stacking interactions in the aggregate state, and thus blocking the non-radiative decay channels. Similar fluorescence enhancement for dithienylethenes $\mathbf{2}$ and $\mathbf{3}$ is observed with the water fraction increased from 0 to $90 \%$ (Figures 2C-F). In addition, the maximum emission wavelength of dithienylethenes $\mathbf{1 - 3}$ are at 495, 491, and $494 \mathrm{~nm}$, respectively, which indicates that various substituents seem to slightly impact the emission of triPE moieties, which may be due to the longer distance between the substituent group and the TriPE fragment. Therefore, these results imply that all the dithienylethenes display obvious AIE properties in the mixture of $\mathrm{THF} / \mathrm{H}_{2} \mathrm{O}$.

As shown in Figure 1, the broad absorption peaks for the closed form 1(c)-3(c) are at the regions of 417-650, 440-68, and
435-662 nm, respectively. Meanwhile, the maximum emission wavelength of these dithienylethenes is at 495, 491, and $494 \mathrm{~nm}$ in the mixtures of $\mathrm{H}_{2} \mathrm{O} / \mathrm{THF}\left(f_{w}=90 \%\right)$, respectively (Figure 2), which are overlapped with the absorption peaks for closed isomers. Thus, the emission may be quenched for the energy transfer from the excited TriPE segment to the ring-closed dithienylethene skeleton (Kawai et al., 2001; Wong et al., 2017). As we speculated, upon irradiation with $254 \mathrm{~nm}$ UV light, the emission intensity at $495 \mathrm{~nm}$ for $\mathbf{1}$ in the mixtures of $\mathrm{H}_{2} \mathrm{O} / \mathrm{THF}$ $\left(f_{w}=90 \%\right)$ gradually decreases, which is accompanied by obvious fading of the green fluorescence due to the formation of the corresponding closed isomer (Figure 3A). The original emission could be restored upon irradiation with $>402 \mathrm{~nm}$ visible light. Furthermore, good fatigue resistance in the mixtures of $\mathrm{H}_{2} \mathrm{O} / \mathrm{THF}\left(f_{w}=90 \%\right)$ is also observed from the view of the fluorescence-switching cycle (Figure 3B). Thus, these compounds display an excellent fluorescent-switching behavior when irradiated with UV/Vis light in the aggregated state.

\section{Fluorescent-Switching Behaviors in the Solid State}

For many applications, especially those that facilitate device integration, the fluorescence switch is ideal for being able to trigger effectively on solid or solid supports (Cheng et al., 2015; Lehr et al., 2015). Next, we further investigate the fluorescent-switching behaviors of these dithienylethenes in the powder state. As displayed in Figure 4A, Table 1, 1 (o) in the powder state emits strong green fluorescence at $\lambda_{\text {em }}$ $=493 \mathrm{~nm}$, which implies a negligible hypochromatic shift, compared to that in the aggregated state $(495 \mathrm{~nm})$. Furthermore, 


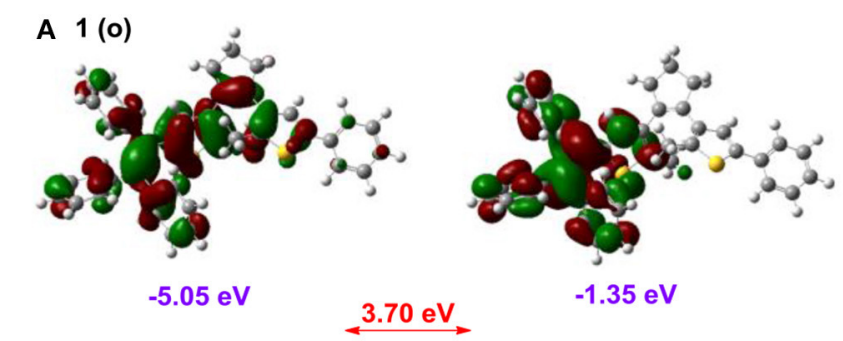

C 2 (o)

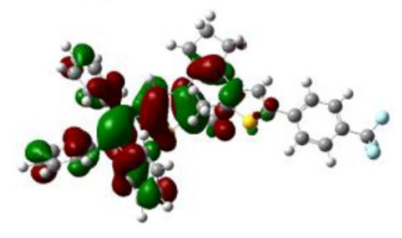

$-5.15 \mathrm{eV}$ $\stackrel{3.71 \mathrm{eV}}{\longrightarrow}$

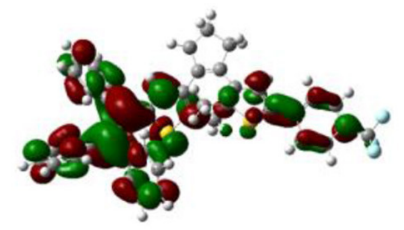

$-1.44 \mathrm{eV}$

E 3 (o)

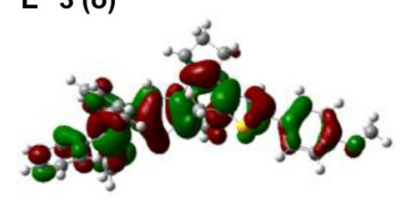

$-5.00 \mathrm{eV}$ $\stackrel{3.67 \mathrm{eV}}{\longrightarrow}$

HOMO

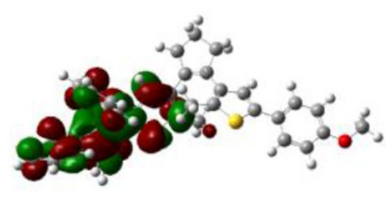

$-1.33 \mathrm{eV}$

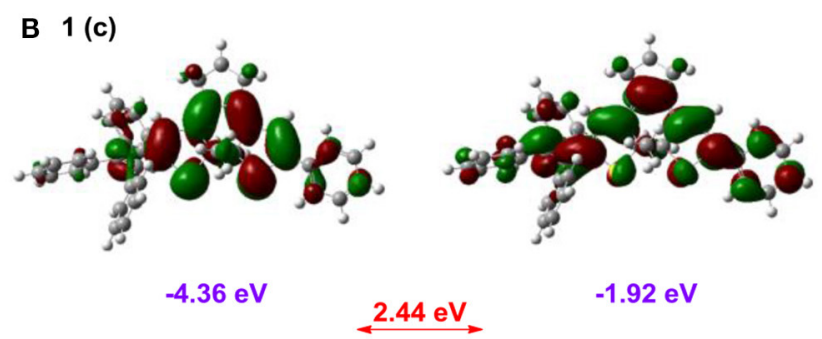

D 2 (c)
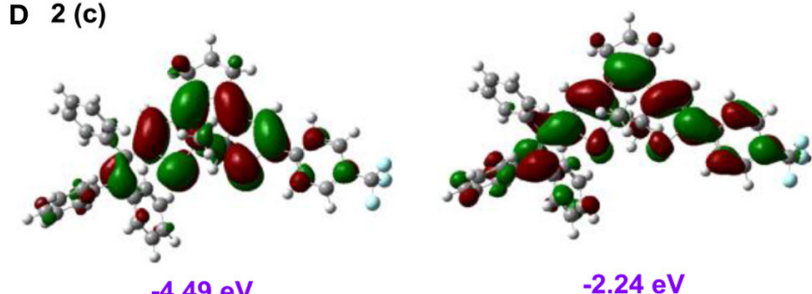

$-4.49 \mathrm{eV}$ $\stackrel{2.25 \mathrm{eV}}{\longrightarrow}$
F 3 (c)
$-4.27 \mathrm{eV}$

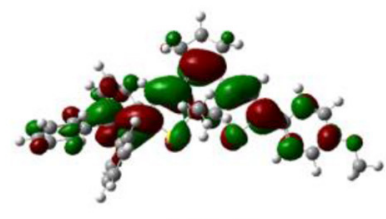

$-1.82 \mathrm{eV}$ $\stackrel{2.45 \mathrm{eV}}{\longrightarrow}$

HOMO

LUMO

FIGURE 6 | Frontier molecular orbital profiles of dithienylethenes 1-3 based on DFT calculations at the B3LYP/6-31G* level by using the Gaussian 09 program, (A) ring-open isomer 1 (O); (B) ring-closed isomer 1 (C); (C) ring-open isomer 2 (o); (D) ring-closed isomer 2 (C); (E) ring-open isomer 3 (o); (F) ring-closed isomer 3 (C).

3 with $\mathrm{OCH}_{3}$ group displays the strongest emission intensity than those of its analogs $\mathbf{1}$ and 2. Similar to that, for the aggregated state, dithienylethene $\mathbf{1}$ exhibits the efficient- and reversible-fluorescence "on-off" process in the powder state upon alternating irradiation with $365 \mathrm{~nm}$ UV light and visible light at $>402 \mathrm{~nm}$. Similar fluorescent-switching behaviors are also observed when the powder state of $\mathbf{2}$ and $\mathbf{3}$ is exposed to $254 \mathrm{~nm}$ UV light and $>402 \mathrm{~nm}$ visible light, respectively, as illustrated in Figures 4B-D. Thus, they can be utilized as a novel fluorescence switch integrated with smart, solid-state optoelectronic materials.

\section{Theoretical Calculations}

To further gain an insight into the relationships between the electronic properties and photoreactivity of $\mathbf{1 - 3}$, their groundstate geometry and electron density are calculated by density functional theory (DFT) in Gaussian 09 B3LYP/6-31G* level (Ditchfield, 1971; Becke, 1993; Frisch et al., 2009). As illustrated in Figure 5A, the energy-minimized structure of $\mathbf{1}$ (o) displays a classical antiparallel conformation, in which triphenylethene moieties attached to the adjacent thiophene group show a propeller configuration. Moreover, the HOMO orbital energy of $\mathbf{1}(\mathbf{o})$ is localized around the triPE and DTE moieties, while its LUMO is mainly distributed over the triPE group due to its poor planarity (Figure 6A). Thus, the results further confirm its AIE properties and luminescence behaviors in the solid state in the experiments, which is mainly because the propellershaped triphenylethene moieties with non-planarity can block intermolecular $\pi-\pi$ stacking interactions in the aggregate state and the solid state. In addition to the triPE group, the closed isomer 1 (c) presents an almost planar conjugated structure (Figure 5B), in which the HOMO is mainly distributed in the DTE center while its LUMO is nearly on the whole molecular skeleton (Figure 6B). As expected, compared with $\mathbf{1}$ (o) $(3.7 \mathrm{eV})$, 1 (c) displayed a narrower energy band gap $(2.44 \mathrm{eV})$ due to the extended $\pi$-conjugation. For the $\mathrm{CF}_{3} / \mathrm{OCH}_{3}$-substituted dithienylethenes $\mathbf{2}$ and $\mathbf{3}$, analogically optimized structures and electron distributions for open and closed forms are observed (Figures 5C-F, 6C-F). Thus, the DFT calculations further validate the above experimental results.

\section{CONCLUSIONS}

In summary, we successfully have developed three novel triphenylethene-functionalized dithienylethenes by introducing triphenylethene moieties at the termini of dithienylethene unit, in which the triPE group functions as an AIE active fragment. They display good photochromic behaviors with excellent 
fatigue resistance upon irradiation with UV $(254 \mathrm{~nm})$ or visible light $(>402 \mathrm{~nm})$ in THF solution. And it has been found out that different substituent groups have a slight effect on their photochromic properties, mainly including the absorption maximum and quantum yields of cyclization and cycloreversion reactions. Moreover, these compounds exhibit AIE properties and luminescence behaviors in the solid state before irradiation with UV light. Upon alternating irradiation with UV/visible light, they display effective fluorescent-switching behaviors in the aggregated state and the solid state. The experimental results have been validated by the DFT calculations. Thus, they can be utilized as novel fluorescence switches for potential application in the fields of optoelectronics and photopharmacology.

\section{DATA AVAILABILITY STATEMENT}

The original contributions presented in the study are included in the article/Supplementary Material, further inquiries can be directed to the corresponding author/s.

\section{AUTHOR CONTRIBUTIONS}

HZhu, CL, and XG performed the synthesis experiments. XH, $\mathrm{XZ}$, and LS conducted the properties. HZha, Y-PZ, LL, and ZL

\section{REFERENCES}

Becke, A. D. (1993). Density-functional thermochemistry. III. The role of exact exchange. J. Chem. Phys. 98, 5648-5652. doi: 10.1063/1.464913

Berberich, M., Natali, M., Spenst, P., Chiorboli, C., and Würthner, F. (2012). Nondestructive photoluminescence read-out by intramolecular electron transfer in a perylene bisimide-diarylethene dyad. Chem. Eur. J. 18, 13651-13664. doi: 10.1002/chem.201201484

Cheng, H. B., Huang, Y. D., Zhao, L., Li, X., and Wu, H. C. (2015). A prominent bathochromic shift effect of indole-containing diarylethene derivatives. Org. Biomol. Chem. 13, 3470-3475. doi: 10.1039/C4OB02619E

Cui, L., Baek, Y., Lee, S., Kwon, N., and Yoon, J. (2016). An AIE and ESIPT based kinetically resolved fluorescent probe for biothiols. J. Mater. Chem. C 4, 2909-2914. doi: 10.1039/C5TC03272E

Ding, D., Li, K., Liu, B., and Tang, B. Z. (2013). Bioprobes based on AIE fluorogens. Acc. Chem. Res. 46, 2441-2453. doi: 10.1021/ar3003464

Ditchfield, R. (1971). Self-consistent molecular-orbital methods. IX. An extended gaussian-type basis for molecular-orbital studies of organic molecules. J. Chem. Phys. 54, 724-728. doi: 10.1063/1.1674902

Dong, H., Luo, M., Wang, S., and Ma, X. (2016). Synthesis and properties of tetraphenylethylene derivatived diarylethene with photochromism and aggregation-induced emission. Dyes Pigments. 139, 118-128. doi: 10.1016/j.dyepig.2016.11.054

Frisch, M. J., Trucks, G. W., Schlegel, H. B., Scuseria, G. E., Robb, M. A., Cheeseman, J. R., et al. (2009). Gaussian 09 (Revision D). Wallingford, CT: Gaussian, Inc.

Fukaminato, T., Doi, T., Tamaoki, N., Okuno, K., Ishibashi, Y., Miyasaka, H., et al. (2011). Single-molecule fluorescence photoswitching of a diaryletheneperylenebisimide dyad: non-destructive fluorescence readout. J. Am. Chem. Soc. 133, 4984-4990. doi: 10.1021/ja110686t

Irie, M. (2000). Diarylethenes for memories and switches. Chem. Rev. 100, 1685-1716. doi: 10.1021/cr980069d

Irie, M., Fukaminato, T., Matsuda, K., and Kobatake, S. (2014). Photochromism of diarylethene molecules and crystals: memories, switches, and actuators. Chem. Rev. 114, 12174-12277. doi: 10.1021/cr500249p designed the experiments. HZha, Y-PZ, and ZL interpreted the data and wrote the paper. All the authors contributed to the article and approved the submitted version.

\section{FUNDING}

This research was supported by the Science and Technology Project of Henan Province (No. 212102210549), national cultivation fund project of Luoyang Normal University (Nos. 2017-PYJJ-005 and 2018-PYJJ006), Innovation and Entrepreneurship Training Program for College students in Henan Province (No. S202010482049), and the Science and Technology Innovation Development Plan of Yantai (2020MSGY114). This work was also supported by Yantai Double Hundred Plan and Talent Induction Program for Youth Innovation Teams in Colleges and Universities of Shandong Province.

\section{SUPPLEMENTARY MATERIAL}

The Supplementary Material for this article can be found online at: https://www.frontiersin.org/articles/10.3389/fchem. 2021.665880/full\#supplementary-material

Irie, M., Fukaminato, T., Sasaki, T., Tamai, N., and Kawai, T. (2002). Organic chemistry: a digital fluorescent molecular photoswitch. Nature 420, 759-760. doi: $10.1038 / 420759$ a

Irie, M., Lifka, T., Kobatake, S., and Kato, N. (2000). Photochromism of 1,2-bis (2methyl-5-phenyl-3-thienyl) perfluorocyclopentene in a singlecrystallinephase. J. Am. Chem. Soc. 122, 4871-4876. doi: 10.1021/ja993181h

Jiang, G., Wang, S., Yuan, W., Jiang, L., Song, Y., Tian, H., et al. (2009). Highly fluorescent contrast for rewritable optical storage based on photochromic bisthienylethene-bridged naphthalimide dimer. Chem. Mater. 18, 235-237. doi: 10.1021/cm052251i

Jiang, G., Wang, S., Yuan, W., Zhao, Z., and Duan, A. (2007). Photo- and protondual-responsive fluorescence switch based on a bisthienylethene-bridged naphthalimide dimer and its application in security data storage. Eur. J. Org. Chem. 2007, 2064-2067. doi: 10.1002/ejoc.200601122

Kawai, T., Sasaki, T., and Irie, M. (2001). A photoresponsive laser dye containing photochromic dithienylethene units. Chem. Commun. 32, 711-712. doi: 10.1039/b100330p

Lehr, J., Tropiano, M., Beer, P. D., Faulkner, S., and Davis, J. J. (2015). Reversible redox modulation of a lanthanide emissive molecular film. Chem. Commun. 51, 6515-6517. doi: 10.1039/C5CC01097G

Li, C., Gong, W. L., Zhe, H., Aldred, M. P., Zhang, G., Chen, T., et al. (2013). Photoswitchable aggregation-induced emission of a dithienylethenetetraphenylethene conjugate for optical memory and super-resolution imaging. RSC Adv. 3, 8967-8972. doi: 10.1039/c3ra40674a

Li, C., Yan, H., Zhang, G., Gong, W., Chen, T., Hu, R., et al. (2014). Photocontrolled intramolecular charge/energy transfer and fluorescence switching of tetraphenylethene-dithienylethene-perylenemonoimide triad with donor-bridge-acceptor structure. Chem. Asian J. 9, 104-109. doi: 10.1002/asia.201301071

Li, H., Lin, H., Lv, W., Gai, P., and Li, F. (2020). Equipment-free and visual detection of multiple biomarkers via an aggregation induced emission luminogen-based paper biosensor. Biosens. Bioelectron. 165:112336. doi: 10.1016/j.bios.2020.112336

Li, H., Wang, C., Hou, T., and Li, F. (2017). Amphiphile-mediated ultrasmall aggregation induced emission dots for ultrasensitive fluorescence 
biosensing. Anal. Chem. 89, 9100-9107. doi: 10.1021/acs.analchem.7b 01797

Li, X., Gu, J., Zhou, Z., Liu, W., Gao, G., and Wang, Q. (2020). Precise control for the aggregation and deaggregation with the aid of a tetraphenylethylene derivative: Luminescence modulation and sensing performance. Dyes Pigments. 172:107844. doi: 10.1016/j.dyepig.2019.107844

Li, Z., Dai, Y., Lu, Z., Pei, Y., and Guo, H. (2019a). Efficient green light-excited switches based on dithienylethenes with BF2-doped $\pi$-conjugated systems. Chem. Commun. 55, 13430-13433. doi: 10.1039/C9CC06838D

Li, Z., He, C., Lu, Z., Li, P., and Zhu, Y. P. (2020). Recent progress in all-visible-light-triggered diarylethenes. Dyes Pigments. 182:108623. doi: 10.1016/j.dyepig.2020.108623

Li, Z., Li, M., Liu, G., Wang, Y., Kang, G., Li, C., et al. (2019b). Synthesis, photophysical properties and NIR photochromism of photoresponsive difluoroboron $\beta$-diketonate complex based on dithienylethene unit. Dyes Pigments. 160, 597-603. doi: 10.1016/j.dyepig.2018.08.034

Li, Z., Liao, L., Sun, W., Xu, C., Zhang, C., Fang, C., et al. (2008). Reconfigurable cascade circuit in a photo- and chemical-switchable fluorescent diarylethene derivative. J. Phys. Chem. C 112, 5190-5196. doi: 10.1021/jp711613y

Li, Z., Pei, Y., Wang, Y., Lu, Z., and Guo, H. (2019c). Blue-/NIR Light-excited fluorescence switch based on a carbazole-dithienylethene- $\mathrm{BF}_{2}$ bdk triad. J. Org. Chem. 84, 13364-13373. doi: 10.1021/acs.joc.9b01508

Li, Z., Qin, M., Du, X., Wang, Y., and Lu, Z. (2019d). Aldehydefunctionalized dithienylethenes with extended $\pi$-systems as versatile building blocks for NIR photochromic materials. Tetrahedron Lett. 60:151166. doi: 10.1016/j.tetlet.2019.151166

Li, Z., Wang, Y., Li, M., Chen, H., and Xie, Y. (2019e). Solvent-dependent and visible light-activated NIR photochromic dithienylethene modified by difluoroboron $\beta$-diketonates as fluorescent turn-on $\mathrm{pH}$ sensor. Dyes Pigments. 162, 339-347. doi: 10.1016/j.dyepig.2018.10.049

Liang, J., Tang, B. Z., and Liu, B. (2015). Specific light-up bioprobes based on AIEgen conjugates. Chem. Soc. Rev. 44, 2798-2811. doi: 10.1039/C4CS00444B

Lim, S. J., An, B. K., Jung, S. D., Chung, M. A., and Park, S. Y. (2004). Photoswitchable Organic Nanoparticles and a Polymer Film Employing Multifunctional Molecules with Enhanced Fluorescence Emission and Bistable Photochromism. Angew. Chem. Int. Ed. Engl. 43, 6346-6350. doi: 10.1002/anie.200461172

Lim, S. J., An, B. K., and Park, S. Y. (2005). Bistable Photoswitching in the film of fluorescent photochromic polymer: enhanced fluorescence emission and its high contrast switching. Macromolecules. 38, 6236-6239. doi: $10.1021 / \mathrm{ma} 0504163$

Lubbe, A. S., Szymanski, W., and Feringa, B. L. (2017). Recent developments in reversible photoregulation of oligonucleotide structure and function. Chem. Soc. Rev. 46, 1052-1079. doi: 10.1039/C6CS00461J

Lucas, L. N., de Jong, J. J. D., van Esch, J. H., Kellogg, M. R., and Feringa, B. (2003). Syntheses of Dithienylcyclopentene Optical Molecular Switches. Eur. J. Org. Chem. 2003, 155-166. doi: 10.1002/1099-0690(200301)2003:1<155::AID-EJOC155>3.0.CO;2-S

Luo, J., Xie, Z., Lam, J. W. Y., Cheng, L., Tang, B. Z., Chen, H., et al. (2001). Aggregation-induced emission of 1-methyl-1,2,3,4,5-pentaphenylsilole. Chem. Commun. 21, 1740-1741. doi: 10.1039/b105159h

Ma, L., Li, C., Liang, Q., Wang, S., and Cao, D. (2018). Wavelength tunable tetraphenylethene fluorophore dyads: synthesis, aggregationinduced emission and $\mathrm{Cl} 2$ gas detection. Dyes Pigments. 149, 543-552. doi: 10.1016/j.dyepig.2017.10.042

Ma, L., Li, C., Yan, Q., Wang, S., Miao, W., and Cao, D. (2020). Unsymmetrical photochromic bithienylethene-bridge tetraphenylethene molecular switches: synthesis,aggregation-induced emission and information storage. Chin. Chem. Lett. 31, 361-364. doi: 10.1016/j.cclet.2019.07.040

Mei, J., Hong, Y., Lam, J. W. Y., Qin, A., Tang, Y., and Tang, B. Z. (2014). Aggregation-induced emission: the whole is more brilliant than the parts. $A d v$. Mater. 26, 5429-5479. doi: 10.1002/adma.201401356

Myles, A. J., Gorodetsky, B., and Branda, N. R. (2010). Photoregulation of luminescence quenching in photochromic porphyrin-phenoxynaphthacene- quinone copolymers. Adv. Mater. 16, 922-925. doi: 10.1002/adma.200306227

Pu, S., Sun, Q., Fan, C., Wang, R., and Liu, G. (2016). Recent advances in diarylethene-based multi-responsive molecular switches. J. Mater. Chem. C 4, 3075-3093. doi: 10.1039/C6TC00110F

Qiang, Z., Shebek, K. M., Irie, M., and Wang, M. (2018). A polymerizable photoswitchable fluorophore for super-resolution imaging of polymer self-assembly and dynamics. ACS Macro Lett. 7, 1432-1437. doi: 10.1021/acsmacrolett.8b00686

Raymo, F. M., and Tomasulo, M. (2005). Electron and energy transfer modulation with photochromic switches. Cheminform 34, 327-336. doi: 10.1039/b4 00387j

Tian, H., and Yang, S. (2004). Recent progresses on diarylethene based photochromic switches. Chem. Soc. Rev. 33, 85-97. doi: 10.1039/b302356g

Tian, S., Luo, T., Zhu, Y., and Wan, J. (2020). Recent advances in the diversification of chromones and flavones by direct $\mathrm{C} \mathrm{H}$ bond activation or functionalization. Chin Chem Lett. 31, 3073-3082. doi: 10.1016/j.cclet.2020.07.042

Uno, K., Niikura, H., Morimoto, M., Ishibashi, Y., Miyasaka, H., and Irie, M. (2011). In situ preparation of highly fluorescent dyes upon photoirradiation. J. Am. Chem. Soc. 133, 13558-13564. doi: 10.1021/ja204583e

Wang, S., Shen, W., Feng, Y., and Tian, H. (2006). A multiple switching bisthienylethene and its photochromic fluorescent organogelator. Chem. Commun. 14, 1497-1499. doi: 10.1039/b515412j

Wang, S., Wang, F., Li, C., Li, T., and Cao, D. (2018). Photo-induced morphology transition of a multifunctional photochromic bisthienylethene molecule with switchable aggregation-induced emission. Sci. China Chem. 61, 1301-1306. doi: 10.1007/s11426-018-9254-6

Wong, C. L., Poon, C. T., and Yam, W. W. (2017). Photoresponsive organogelator: utilization of boron(III) diketonate as a building block to construct multiresponsive materials. Organometallics 36, 2661-2669. doi: 10.1021/acs.organomet.7b00274

Yao, X., Li, T., Wang, J., Ma, X., and Tian, H. (2016). Recent progress in photoswitchable supramolecular self-assembling systems. Adv. Opt. Mater. 4, 1322-1349. doi: 10.1002/adom.201600281

Yu, Q., Su, X., Zhang, T., Zhang, Y., Li, M., Liu, Y., et al. (2018). Noninvasive fluorescence switch in polymer films based on spiropyran-photoacid modified TPE. J. Mater. Chem. C 6, 2113-2122. doi: 10.1039/C7TC0 $5142 \mathrm{E}$

Zang, S., He, W., Zhou, Z., Han, Z., Li, S., Zhou, Z., et al. (2021). Ultrafast size expansion and turn-on luminescence of atomically precise silver clusters by hydrogen sulfide. Angew. Chem. Int. Ed. 60, 8505-8509 doi: 10.1002/anie.2021 00006

Zhang, J., and Tian, H. (2018). The endeavor of diarylethenes: new structures, high performance, and bright future. Adv. Opt. Mater. 6, 1701278-1701307. doi: 10.1002/adom.201701278

Zhang, J., Wang, J., and Tian, H. (2014). Taking orders from light: progress in photochromic bio-materials. Mater. Horiz. 1, 169-184. doi: 10.1039/C3MH00031A

Zhou, Z., Li, B., Shen, C., Wu, D., Fan, H., Zhao, J., et al. (2020). Metallic 1T phase enabling MoS2 nanodots as an efficient agent for photoacoustic imaging guided photothermal therapy in the near-infrared-II window. Small 16, 2004173. doi: 10.1002/smll.2020 04173

Conflict of Interest: The authors declare that the research was conducted in the absence of any commercial or financial relationships that could be construed as a potential conflict of interest.

Copyright (C) 2021 Zhang, Hu, Zhu, Shen, Liu, Zhang, Gao, Li, Zhu and Li. This is an open-access article distributed under the terms of the Creative Commons Attribution License (CC BY). The use, distribution or reproduction in other forums is permitted, provided the original author(s) and the copyright owner(s) are credited and that the original publication in this journal is cited, in accordance with accepted academic practice. No use, distribution or reproduction is permitted which does not comply with these terms. 